\title{
Recalculation of the Solvency II Transitional Measures on Technical Provisions
}

\section{Abstract of the Edinburgh Discussion}

[Institute and Faculty of Actuaries, Sessional Research Event, IFoA Working Party, Edinburgh, 28 November 2017]

This abstract relates to the following paper: Cooke, J., Scott, A., Smith, D., Rogan, A., Cooper, R. Morgan, S., Plotnek, A., Kenyon, N. and Bhalla, S. Recalculation of the Solvency II transitional measures on technical provisions. Institute and Faculty of Actuaries. https://www.actuaries.org.uk/ documents/recalculation-solvency-ii-transitional-measures-technical-provisions

The Chairman (Mr C. M. Murison, F.F.A.): I am Craig Murison from Lloyds Banking Group and I have the honour of chairing tonight's meeting. Welcome to the discussion about the Recalculation of the Solvency II Transitional Measures on Technical Provisions (TMTP) paper by the TMTP working party.

The recalculation of the "transitional" has been a hot topic for many of us involved in Solvency II. It now represents a huge component of the Solvency II balance sheet for many UK insurers. The treatment and calculation of the transitional is evolving rapidly.

The paper has raised several questions about the practicalities of calculation.

We have seen some potential material changes in the way in which it will be calculated as at the end of 2017 owing to some guidance from the Prudential Regulation Authority (PRA) during the year on the application of one leg of it called the Financial Resource Requirement (FRR) test.

It raises interesting questions about the use of the transitional generally as an Asset-Liability Management (ALM) tool. How should your risk asset statements reflect the additional benefit that you take on to your balance sheet; and how should it reflect the fact that it then runs off over time?

Finally, looking further ahead, you might be seeing more change through simplification or political change through Brexit. What might that mean for the calculation of the transitional over the next few years?

I will now introduce our two speakers. First, Susan Morgan has been with Prudential since 2010 in a variety of different Solvency II related roles. She is currently the Solvency II controller and responsible for first line governance of the internal capital model.

She is also a member of the Life Solvency and Capital Management Research Group which, she has told me beforehand, has been running for 10 years in its current guise.

The group has produced papers on practical implementation challenges for the internal models and expert judgement. 
Andy Rogan has worked at Lloyds Banking Group for a long time in a variety of roles over that period from with-profits to capital optimisation. He is now the senior manager within the ALM team, with responsibility for annuity ALM.

Susan is going to introduce the paper.

Ms S. M. M. Morgan, F.F.A.: On the agenda, I am going to cover what the TMTP is. That is how we refer to it now. Why do firms have a TMTP? How is the TMTP calculated?

Andy will go on to talk about how the TMTP is recalculated and the recent changes, particularly from the PRA.

So, what is the TMTP? It allows the Solvency II technical provisions to be reduced. That reduction runs off linearly from the date that Solvency II came into effect on 1 January 2016 for 16 years.

It largely allows your balance sheet to be broadly equivalent to your Solvency I balance sheet on day 1.

It came into force as a result of the long-term guarantees package as part of Omnibus II, which amended the original Solvency I directive.

If you are interested in knowing the specific rule, it is Article $308 \mathrm{~d}$ in the Level I directive. That was taken into UK law in 2015 as part of the statutory instrument number 575. It was section 54. It was within that statutory instrument that you see the issues with double run-off.

There is little information in the Solvency II rules about the TMTP in general, so the PRA has issued a couple of supervisory statements that go with it. The first was number 17 in 2015 . Then it issued another supervisory statement in 2016, number 6. It updated that in April of this year when it issued Policy Statement 11.

Why do firms have a TMTP? The working party think that one of the key reasons for having a TMTP is to deal with the material difference between the Solvency II technical provisions and Solvency I: the risk margin.

For annuity writers, the risk margin can add between $10 \%$ and $25 \%$ to the best estimate liabilities. The $25 \%$ is largely relating to the deferred annuity part of non-profit annuities.

There are other reasons for differences between Solvency II and Solvency I, a couple of key ones being contract boundaries and the differences between the risk-free rate under Solvency II and the discount rate that you might have used under Solvency I.

It is helpful because on day 1 you could have had quite a big strain on your balance sheet that would have been detrimental to the ability to write new business or to pay dividends, and it could have made funds take management actions that they would not otherwise have to take under the Solvency I regime.

If you cannot cover your Solvency Capital Requirement (SCR) under Solvency II without the use of a TMTP, you are required to submit a phasing-in plan to the PRA. That plan sets out the 
actions that you are going to take for the write-down of the transitional over the period of 16 years. You need to submit an annual update to the PRA on how you are progressing against that plan. If for any reason you have a material change in risk profile and you are applying for a recalculation of the TMTP, you will also have to provide the PRA with an update on that phasing-in plan.

How is the TMTP calculated? There are three main steps to the calculation. The first step is to compare your Solvency II technical provisions of best estimate liabilities and risk margin to your Internal Capital Assessment (ICA) market-consistent liabilities (MCLs). Those ICA MCLs need to include any Individual Capital Guidance that you had on your technical provisions from the PRA when the previous regime was in effect.

This step in the calculations only applies to business that was in force when Solvency II came into effect, so pre-1 January 2016 business.

You also did not have to apply for all business on your book. You could apply for subsets of the business. If you did apply for a subset, you had to demonstrate that they all had similar risk characteristics, so they were known as homogeneous risk groups.

The next step is the FRR test. It requires you to ensure that once you have applied a TMTP, you do not end up in a position that would have been better had you been under the Solvency I regime. You cannot have lower liabilities and capital than you would have had previously.

Unlike the first step, which only has you looking at Solvency I, Pillar 2, the ICA part, the FRR test requires you to compare your Solvency II capital and liability requirements to the more onerous of Solvency I Pillar I or ICA.

Another difference to step one is that the PRA recently, as part of the PS11/17 update, stated that this part of the test needs to allow for all business, not just the business that was written before 1 January 2016.

That has a consequence where you can make your FRR test bite less, purely by writing new business that is more onerous under Solvency II than it was under Solvency I. Andy [Rogan] is going to cover that in more detail.

The final step in the calculation is to compare step 1 and step 2 to get your final TMTP. An alternative way to think about it is to do step 2 excluding the existence of TMTP. When you get to step 3 you are just looking at the minimum of step one unrestricted transitional and the difference between the capital requirements under Solvency II and Solvency I.

Mr A. I. Rogan, F.F.A.: Susan has done a preamble on what our paper is all about. I am going to talk to you about how to calculate the TMTP.

Way back in 2015, everybody was working hard to get their balance sheets ready for Solvency II: internal models approvals, matching adjustment approvals, transitional approvals - a great deal of hard work just to get a transitional on to the day 1 balance sheet.

So, job done. It will just run-off nicely. Well, that is not quite the case. There were a couple of instances where that run-off does not apply or we need to do something differently. First, regulations 
allow a change following a materially changed risk profile. That requires an application to the PRA. It could be for a number of reasons: Part VII transfers, new reinsurance arrangements, matching adjustment approval, or a change in operating conditions.

There was a supervisory statement (6/16), which gave guidance on the material changes in profiles and what kind of triggers the PRA might expect.

It helpfully, or unhelpfully, gave an explicit criterion that, generally, recalculations would only be allowed as the result of a $5 \%$ or greater change in solvency ratio.

In 2016, everybody is taking a breather after getting Solvency II over the line and then along comes Brexit, resulting in sharp falls in interest rates; firms' risk margins rocketed and that resulted in a significant number of applications to PRA to recalculate their transitional: 16 out of the 33 firms that had approval to hold a transitional in the first place.

Recalculation is also relevant now in the run-up to year-end production of Solvency II balance sheets to the extent that the PRA recently clarified that the expectation of firms is to do a recalculation every 2 years, and that is every 2 years from the date of Solvency II implementation, not 2 years from the date of the last recalculation.

All those 16 companies that recalculated just over a year ago will be recalculating again 18 months from their last recalculation, in most cases.

The working party was set up in April 2016 to start thinking about how we recalculate again and pulled together the paper that was released a couple of months ago.

When we first started the working party, we identified many themes that we thought that we should look at in more detail. There is an interesting one around segregation of business, particularly for pre- and post-2016 business. We must segregate for the purpose of calculating the unrestricted transitional, and recent guidance from the PRA states that we should not segregate for the FRR calculation.

Segregation of business is no easy thing to do and could require a great deal of work, depending on how your systems and processes are structured.

Everybody was excited about bringing in new internal models that were super-efficient and calculated everything perfectly first time and you could jettison old models and just look forward.

That is not the case for the recalculation of the TMTP. Firms will have to hold onto some form of legacy models. The degree to which they will need to hold these will depend on their policy and materiality, but it is certainly an overhead for the industry.

The working party also felt that the transitional recalculations should be proportionate. It did not feel that it was practical for every firm to do a full recalculation of its ICA balance sheet and its Solvency I, Pillar I, balance sheet, every time it wanted to recalculate a transitional. There had to be some easier way to do this that was materially correct. 
The other thing that we identified is that transitionals are firm-specific. We have given you some examples of how we might recalculate certain aspects of the transitional. Certainly, if we went down every branch of every tree to cover every single possibility, I suspect that we would not have published the paper in the transitional's lifetime of 16 years.

Next, I will talk about some key aspects of the recalculation, and key drivers of the differences between the Solvency I and the Solvency II regimes.

The first example, the risk margin, gives you an example of something that is new for Solvency II. The second example is something that is similar but different between regimes. And the third one is certainly something that many of you will love or hate from the previous regime.

The risk margin is quite possibly the biggest component of the transitional. It is material and sensitive to interest rates, as we all experienced in 2016. It does need to be segregated, certainly for the unrestricted calculation.

There is a whole load of material about how to segregate, what to do with increments and how do you carve up your non-market risk capital requirements. That is where your full risk margin is probably diversified across all your business.

A potential solution is to build a complicated model. That could be onerous, depending on how your data and systems work. There is potential maybe to be more proportionate, perhaps looking at your January 2016 model and doing some adjustments to that, such as re-running material risks. The risk margin is a material component of the transitional, so something to take seriously and make sure you do something that is appropriate.

We have the matching adjustment under Solvency II and an illiquidity premium under Solvency I, Pillar 2 - similar but different.

There are some practical things to think about here. The matching adjustment uses your defined deductions, whereas the illiquidity premium under ICA typically uses an internal view. How do you keep that internal view alive in a proportionate manner?

The matching adjustment is stricter on asset eligibility. So there is a theoretical debate to be had. There are assets on the balance sheet that we think work well under the Solvency II matching adjustment, but would you hold them under ICA? Are there assets that we would want to hold under ICA that we do not hold under Solvency II?

A matching adjustment portfolio is ring-fenced under Solvency II. Do you have to go down the route of holding four portfolios, four hypothecations of your matching assets pre- and post-2016, and illiquidity premium and European Insurance and Occupational Pensions Authority (EIOPA) only? Maybe that is overkill. Maybe you can just look to your portfolio overall and pick the relevant assets under each regime. Maybe that is a simplification but it is a sensible one to adopt.

Finally, any kind of Individual Capital Guidance (ICG) that applies under ICA is essentially a drag on the transitional. You must think about how you go about recalculating the transitional. 
One method might be to align your ICA assumptions to Solvency II. You might think that that would remove the ICG from your ICA numbers. That obviously needs some approval from the PRA. The PRA has said that it is interested in understanding how the ICG is recalculated under a TMTP recalculation. It will review it on a proportionate basis. But, it is the PRA who has calculated ICG in the past, so trying to work out how it does it and then apply it is also a challenge. Again, there are many ways to do it. You can be very thorough, and that might be appropriate if you have a particularly large ICG, or you may do something more proportionate where your ICG is some function of a risk exposure and then maybe you can use your Solvency II SCR to approximate it.

I will now go through the recent changes. In April 2017, the PRA issued Policy Statement 11/17, which was a refresh and update of a supervisory statement of the previous year. The PRA stated that the recalculations should be based on up-to-date information. Credible best estimate assumptions should be consistent. That does not necessarily mean that there has to be an equalisation across Solvency II and Solvency I. It is just to make sure that your ICG is appropriate.

The PRA has clarified that the recalculated transitional is an upper bound on the amount that you can put on your balance sheet, so you can reduce that if you so wish. That might be to reflect the true underlying value of the transitional at any point of time, given its irregular recalculation nature. Of course, if your underlying transitional reduces below the triggers to recalculate it, then you would have to recalculate the upper bounds. It is an asymmetric dynamic recalculation of sorts.

For an effective risk management process, the TMTP should be recalculated under a range of stresses and scenarios in the Own Risk and Solvency Assessment.

There is an operational overhead in terms of recalculating something under stress and maybe allowing for it in your projections as well.

Possibly the most interesting one is the FRR test - how we apply the restriction, if one applies.

I was privy to a survey from a well-known consultancy recently. It surveyed firms on how they approached the FRR, and whether they allowed for post-2016 business and the recalculation of it. This was before the supervisory statement came out. Probably about $70 \%$ said that they did not allow for it in the recalculation.

However, the policy statement from the PRA clarified that you should allow for new business in the calculation of the FRR.

Consider a graph showing the run-off of the transitional, assuming a flat run-off, if post-2016 business is not allowed for in the FRR.

The FRR is the biting constraint, and the unrestricted transitional runs off to zero in 16 years, and so does the restricted transitional. There is a linear run-off. The restricted transitional is always the biting constraint.

Now consider a graph that assumes that business leaving the books is offset by new business coming on. We are looking at an FRR including all business, not just pre-2016. What we see is the restricted 


\section{Recent changes (continued)}

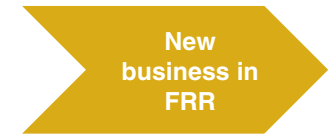

The PRA clarified that the FRR should include all business, not just business written prior to the introduction of Solvency II

Where a legal entity has a TMTP with a restriction, new business will generally act to reduce this restriction and increase the TMTP
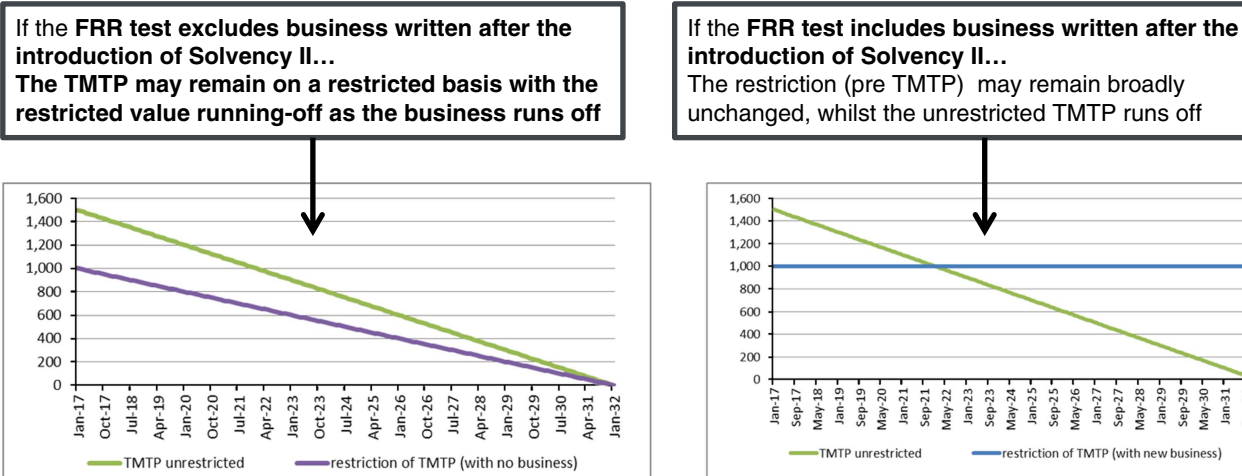

Under certain circumstances this may result in business written after the introduction of Solvency II benefiting from a TMTP

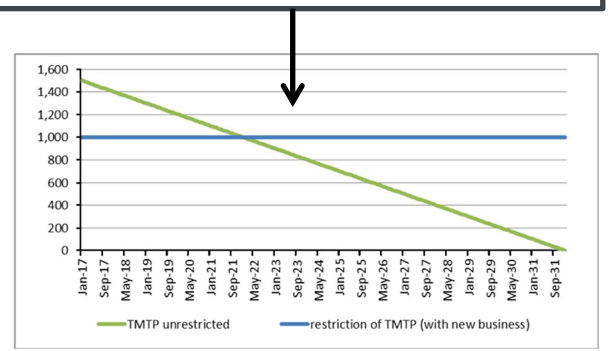

TMTP remaining flat for 5 or so years and then the unrestricted transitional takes over. We have a flat line and then we start to go down the diagonal.

Under the two methods, over the fullness of time, you are probably going to get to the point where your unrestricted transitional bites and you are going to run-off in a timely manner. What it means is that, in the short term, many firms will now get some form of capital relief, certainly on the risk margin on the new business that they write.

What are the implications of that? It means that shareholders probably get their dividends a little sooner for a few years, and also some companies may decide to reflect this benefit in their pricing and they will win more business if they choose to do so. It is an interesting dynamic. I am not sure if it is a necessarily intended consequence of the transitional when it was first devised.

I shall now move on to the remaining challenges. The TMTP is a complex calculation. It takes a great deal of time and effort to produce. It is the difference between two very large numbers.

Every time a firm does a major model change or a change of business, what is the impact on the transitional? Does it need to be recalculated?

For example, if you have a Part VII transfer coming and you are trying to work out what your new transitional should be, you might be in a situation where you do not have the information on the transferring business that you need to do the recalculation.

There is an opportunity cost associated with the transitional. It takes up a lot of management time and resources, reporting to boards, and so on. Applications can take a long time to write, and even 
longer to get approved. There is a significant overhead in managing the transitional. Some people may think that is a distraction in running your business in a Solvency II world.

I should mention the application process again, as it is a potentially laborious task. The working party suggested that the transitional's recalculation under a change in operating conditions should be more dynamic. When we see interest rates move around, ideally we would have a policy in place agreed with the PRA, and if the triggers in that policy are met, we proceed to recalculate. There would certainly be benefits in terms of the time taken to apply. It would be potentially easier to explain to management and in external disclosures.

One thing that was pleasing in the recent policy statement was the number of times the PRA used the word "proportionate" or "proportionality". Firms should bear that in mind when producing their policies and doing their recalculations. A helpful example is the 2017 recalculation process. There is much debate about whether firms must go through a full recalculation application process, or whether it would be more streamlined and simplified. We are at a sensible place where we send just a letter to the PRA, stating that we intend to recalculate, and the PRA will confirm that that is okay. This is a straightforward process, rather than having to do reams of documentation to justify why you may want to make that change. That is indeed helpful.

Here is a summary of the discussion and the key takeaways. The risk margin is clearly a material item of the transitional. Essentially, the transitional is about a soft landing into Solvency II. Given the materiality of the risk margin, I think the transitional's primary objective is to mitigate the introduction of the Solvency II risk margin.

The calculation is complex and can be onerous and requires at least three stages of calculation.

Recalculation is an ongoing challenge for firms. Certainly, when many recalculations were done last year, while it was not great to recalculate immediately after the implementation of Solvency II, firms did at least have the old Solvency I models at 31 December 2016 to look back to. That was helpful. Obviously, as we move through time, those models become less relevant and the materiality of the transitional reduces. There is a big onus on firms to make sure that their recalculation policy remains appropriate and proportionate.

The recent policy statement has brought clarity in several areas, but challenges remain.

The Chairman: My overwhelming takeaway was that this is complicated. Against the backdrop of the Treasury Select Committee's recent pronouncement on the PRA's implementation of Solvency II, do you see there being a simplification of the methodology in the relatively near future, or not?

Ms Morgan: We did discuss this as a working party. It was before the Treasury Select Committee made their pronouncements. We thought it might get more complex in the shorter term as the PRA issues more guidance, as funds develop in the way that they might recalculate; but, then, as it starts to run-off and becomes less material, there will be more scope for approximations and simplifications. 
There was a matching adjustment consultation paper issued, I think, in the last few weeks. At the bottom of that statement, there was something from the PRA stating that it was going to continue to look at the recalculation of the TMTP.

It could be that we get something from the PRA soon that does allow more simplifications.

Mr S. J. Makin, F.F.A.: I have sympathy with Craig [Murison's] comment that there is a huge amount of complexity and was struck by the aphorism that if you could start from somewhere, it would not be here.

Thinking ahead to Brexit, what simplifications do you think we should be pushing for as an industry in the context of TMTP and its recalculation, maybe in relation to the three main areas?

You said it was used for risk margin, illiquidity premium and ICG. What are the things that we should be pushing hard on, do you think?

Ms Morgan: This is an area that is going to get looked at in general and not just in terms of TMTP. If there was a case after Brexit, where the cost of capital associated with the risk margin came down, then you are going to end up with a raft of recalculations of your TMTP anyway because it would reduce, given that you are losing a big element of it.

The PRA put responsibility onto the audit committees approving the amount of the TMTP, because the PRA do not approve the amount of the transitional that you have.

It will approve that you have had a material change in risk profile or that you have reached the 2year point. But then it is up to the audit committee to sign off that you still comply with the FRR test and that you meet all the conditions in the statutory instrument.

Unless that was changed, it is difficult to see how you can start introducing many simplifications unless you can get your own audit committee comfortable with what you are doing.

Mr Rogan: I guess that there is a cultural element within firms. I am sure some firms are recalculating the transitional to the penny using a full ICA and Solvency II balance sheet comparison. I am sure other firms are being more proportionate in their approach, maybe adjusting the 2016 risk margin, interest rates and other key risk movements.

Mr P. Turnbull, F.I.A.: The TMTP approach to transitioning from Solvency 1 to Solvency II is surprisingly complex and resource intensive. A similarly significant change to the taxation of life companies in 2013 created a need for a transitional adjustment. HMRC used a 10-year straight line taxable profit adjustment. I am not sure why a similarly simple transition was not applied for Solvency II. Further the use of the TMTP approach effectively prolongs the life of the Solvency 1 measures. Given the continued significance of Solvency 1 , I have been surprised at the difficulty that I had finding the Solvency 1 Rules on the PRA website.

Mr D. J. Campbell, F.F.A.: I agree entirely with Paul [Turnbull]. What is worse this that the new supervisory statement means that is not just true on day 1. In Andy Rogan's example, it would be 
true for the next 5 years as well. And it will delay even further the point at which the Solvency II regime starts to have an impact on companies.

Mr J. E. Gill, F.F.A.: Did you ever question whether the constraints were appropriate? And, in particular, whether the risk margin is right or not?

I know it took 10 years of wrangling over Solvency II to get to the end of the risk margin. But 16 years is an even longer period to live with something that may not be fundamentally sound.

Maybe changing the constraints would be a different way of looking at this problem.

Mr Rogan: We did not look at changing the constraints in the way that you describe. The rules are the rules; this is what we must live with, in the short term at least. How do we make the best of what we have?

Of course, there is a debate as to whether the risk margin is appropriate. Brexit throws that into the fore as well. It was not something that we necessarily considered in detail.

Ms Morgan: We have the risk margin. It is a big part of the difference between Solvency II and Solvency I. How would you go about dealing with that?

Until the PRA stated you still needed to do the FRR test, the main driver of your transitional was the risk margin. The simplest calculation is to look at movement in the risk margin and just run that off over 16 years and ignore everything else.

But the PRA did state that it wanted you to state that you were still meeting the conditions of the FRR test, and then its most recent statement is that you now need to bring in new business.

It is making it more complex. It takes away from the purity of looking at what drives your TMTP and focussing on that component.

Ms K. S. Roper: Can you throw any light on the regulator's motivation to bring new business into the FRR test? It seems hard to understand why.

Ms Morgan: I do not know its thinking. My guess would be it is because there is a need to look at the legal entity level, and the legal entity level brings in all business, even business that is not within the scope of having a transitional in the first place.

We did not talk about it in the presentation. For firms that have ring-fenced funds, the PRA's requirement to look at your legal entity solvency coverage ratio causes some issues; and looking at what the $5 \%$ movement means. When you bring in the ring-fenced funds, you do not look at the owned funds associated with that but the PRA seems to be quite set on the legal entity component. I think it allows easier reconciliation to what is in your Quantitative Reporting Templates. But it has not made any statement.

Mr Rogan: I am not sure the PRA has explicitly recognised what this might do to insurers' balance sheets at the end of this year. The reality is there will be several companies that will see a material uplift, albeit it will then change the run-off. I am not entirely convinced that that is well understood. 
Mr G. Ritchie, F.F.A.: I have a couple of miscellaneous observations. The first is about standardisation. I think that standardisation is doomed to failure. It might be relatively straightforward to say this is the method that one must use for today's Solvency II number. But obviously, as we have seen set out in the paper, there were several approaches in the old Solvency I, Pillar 2, regime. There is always going to be that difference.

My strong view is that we are looking for simplification plus margins. I agree with Andy [Rogan] when he said that too many companies are getting into too much detail.

The second observation is that buried in section 4.1, I think, there is an important point: we might have complexity, but it is our job as actuaries to make sure it is not complex when presented to senior management and boards. The equivalent scenario would be, for example, interest rate or inflation sensitivity, if you are a bulk purchase annuity writer. I think it is important to give the senior decisionmakers in insurance companies the information that they need to manage the business.

I have one last point. We are talking here about a degree of detail. How does the TMTP run-off? The big picture is, as we are going forwards, there will be more new business, more risk margin, and less TMTP, no matter what the run-off pattern is. So, there will be much more sensitivity to, for example, interest rates; and much more volatility on Solvency II balance sheets.

How are we as a profession going to help our employers manage that?

The Chairman: Any comments?

Mr Rogan: I think they are all fair points.

Mr Turnbull: I just wondered: Does Europe implement this in the same way? Are they requiring the same level of recalculation as the United Kingdom?

Ms Morgan: It is not something that we have discussed in detail. But if you look at the article in the Level I directive, there is very little in there about recalculation of TMTP. It focusses very much on day 1. It talks about looking at the difference between the Solvency II technical provisions and those that firms were required to hold under Solvency I.

It states that supervisors may, if they choose, decide to restrict the amount of that transitional, which is what the PRA has done with the FRR test. But we do not have any information as to how other regulators have applied that.

Mr Turnbull: To me, it discourages risk management if you find Solvency I, Pillar 1, applies. Why would you do any further risk management until the Pillar 1 measure is significantly reduced in its impact on capital requirements? TMPT is preventing the very thing that Solvency II is trying to encourage.

I understand the concept that companies should be proportionate in their efforts to calculate TMTP. However, a company's dividend capacity is constrained by capital requirements net of the TMTP and for some companies this maybe the most significant metric. If a company 
spends significant effort producing Solvency II numbers, why would it not spend the same amount of time producing the value that constrains the dividend?

Ms Morgan: I think that that is right. The TMTP acts as a good hedge to movements in the risk margin, or it would act as a good hedge if you could have dynamic recalculation of it. Therefore, you would need to consider a new triggering management action that you otherwise would not take.

Mr Rogan: I would say that proportionality does not necessarily mean that you cut every corner to come up with a fag-packet number. It needs to be robust and appropriate, still.

The Chairman: To what degree have you thought about ALM, and the risk management strategies that you adopt where you do have a big TMTP in your balance sheet?

Given the potential for regulatory change, do you feel that is an area where companies truly are arbitraging the value of the transitional? Or is that not something that the working party looked at?

Ms Morgan: We have not had much information from companies about that. Our focus was primarily recalculation. There is a section in the paper about ALM.

I think that the PRA have issued statements, possibly a directors' update or perhaps the supervisory statement from 2015, in which it expects firms still to have appropriate risk management frameworks in place and ALM strategies that are not dependent on the existence of the transitional.

Mr Rogan: Yes, I tend to agree. I think, at the moment, the transitional is a good hedge on interest rate risk. But when you are at an unrestricted TMTP, it becomes important to hedge and manage the interest rate exposure on the risk margin on your post-2016 business. Maybe firms now have had the luxury of the transitional. But more thought on ALM strategy is to come in the coming years.

Mr J. R. Crispin, F.F.A.: Having been on the Life Board at the time that the working party was established, I reflected on the reasons for it.

We had just had a meeting with the PRA and it was clear that it had not worked through, and were not prepared for, the issues on the recalculation of the transitional. It had been heavily focussed on implementation of Solvency II and planned to think about the transitional in the quiet spell immediately after the start of Solvency II.

Interest rates plummeted and several companies demanded recalculation. It was not ready for it. There would be some firms who would have wanted just a straight, smooth run-off of the transitional, and not be so exposed to interest rates and other factors; whereas others have almost relied on it, particularly in 2016, to manage their capital position. I think that some of it is driven by what we have pushed.

I think that Europe generally does not rely on the transitional; it is more a UK-focussed issue. Europe relies more on the interest rate.

Mr Rogan: Yes, I think that is fair. On the point on wanting a flat run-off, you could always hedge out the residual exposure, if you wanted to. Obviously, that would produce volatility 
on your International Financial Reporting Standards balance sheet as it would become a naked hedge.

Mr M. G. Kerr, F.F.A.: I have been thinking about external disclosures. They seem to be growing in complexity along with the growing complexity of the calculations. We have different approaches to the annual drop of the TMTP. I think it is officially on 1 January. It depends. If you are publishing year-end results, do you drop it before 1 January, so do you effectively drop it on 31 December? If you recalculate on 31 December, do you include the following 1 January's annual drop?

There was the issue last year that you mentioned about Brexit and many companies recalculating transitionals at 30 June. By the end of the year, interest rates were higher, and companies were nervous about quoting transitionals based on such low interest rates and so effectively came up with another form of transitional that they wanted to disclose to the market.

So, there does seem to be growing diversity and complexity in the message that we are giving externally about the transitional. I was wondering whether you thought that there might be anyway in the future that there might be more standardisation or that companies might come to a more uniform view on how they are going to message the transitional externally.

Mr Rogan: That is a difficult one to answer. I think all the observations that you make are fair. I saw a recent survey that suggested maybe $50 \%$ of companies were running off at 31 December and $50 \%$ are running off at 1 January, which obviously has implications for your published 31 December balance sheet.

I keep saying that the transitional is complex and there are many ways of doing it. That flows through into how people report it and show it as well.

The working party paper does suggest that maybe a more dynamic recalculation might be appropriate. That would certainly avoid having to give two sets of numbers in reports and accounts, if you are worried about the level of your underlying transitional versus what you have calculated or put on your Solvency II balance sheet.

It feels like one of these areas where Solvency II was trying to standardise but we are not anywhere near that.

Ms Morgan: EIOPA issued some guidance prior to year-end 2016 that tried to pick up on the 1 January versus 31 December issue. It knows that the rules state that it is 1 January but that many funds report as at 31 December.

If you did not include that run-off as at 31 December, you are supposed to be disclosing a position that is a true and fair reflection of the firm and therefore you would have to do some sort of supplementary disclosure to say that the next day you are going to lose that amount of the TMTP. 
I think that it also stated that, although it refers to an annual run-off, you could run it off quarterly; you need to tie it in with quarterly balance sheet reporting so you do not have a step change at the end of the year.

The PRA put something in its update to SS6/16 about disclosures and stated that you could have a notional amount disclosed as part of your supplementary information. But they would expect you to take a consistent approach when you are reporting internally. But whether we get standardisation, and whether the PRA were to come out and say you cannot disclose more than the maximum, even if it is in supplementary information, I do not think so.

Mr Rogan: You can have different approaches in your forms across firms. The detail is buried somewhere in your disclosures that analysts may or may not choose to read or understand.

Mr I. J. Rogers, F.F.A.: I am interested in the extent to which, following on from the comment from James [Crispin] about this working party being set up on the basis of the PRA not having had a chance to think about this fully, you feel that the PRA has listened to your thoughts on recalculation, and to what extent your work has shaped the regime that we now find ourselves in in terms of the way that the recalculation works.

Ms Morgan: That is a good question, Ian. It is difficult to second-guess what the PRA has concluded on. One of the conclusions of our paper is that it is difficult to get a one-size-fits-all approach and therefore it needs to be fund-specific, so it is helpful that the PRA has not stipulated how you should go about doing a recalculation.

We like to think that the Working Party has helped. There was also an Association of British Insurers working party that was feeding into the consultation papers that were going out.

Mr Rogan: I think they probably should do that as an opportunity rather than a constraint. Certainly, we engaged the PRA as a working party before we published our paper and it had a good look at it. I am not sure that I was privy to those conversations, but I do not think that there are any material objections to the way that it was originally drafted.

The Chairman: One of the things that came out of reading the paper was the working party's preference for a dynamic resetting of the transitional. I guess good management of your balance sheet should see you calculating the value of the transitional anyway outside the formal reset environment and forecasting it forward for business planning.

What do you think the real benefit of introducing that dynamic reset would be against what should be best practice anyway?

Mr Rogan: I agree with you that firms should be keeping an eye on the underlying value of the transitional. They must do that because we need to look at whether they meet their reset triggers.

If they are doing that, then why have the distraction of having to do formal applications every so often? I guess it saves having a policy where a pre-agreed approach to recalculate saves distraction for both firms and PRA alike. 
The other aspect is around clarity of information, both to decision-makers' boards and to external publications. It is nicer to have one number than to have two numbers with a great deal of commentary around them.

The Chairman: I will just wrap up my key takes on the discussion.

We started off with Susan Morgan describing the methodologies and the calculation of the TMTP, which led on to a debate on technical and practical challenges. I think an overriding theme was the complexity, and the benefits that we might get from simplification.

I think Gordon Ritchie's contribution was a valid one. I think it is important - excuse the pun in the surname - that we do see the wood from the trees in all of us, Gordon; that we do focus on what we are trying to manage once the transitionals have run-off materially and are no longer there and that that is what should drive good practice.

We talked a little in a similar vein about risk management, ALM and whether we had companies taking advantage of the TMTP and coming up with practices. I am not sure we had any compelling insight on that one - probably as it is not within the terms of reference in the working party.

This issue of run-off on 31 December or 1 January is a good example of where we can potentially influence the standardisation process to get people operating in a similar vein.

Has the PRA listened to what the working party has done while not necessarily plugged into it? I think it was helpful to hear your views that the lack of prescription from the PRA does feel like that is helpful, and that the reality is that it is not a one-size-fits-all case of calculation and application of the transitional across the industry.

The only thing that is certain is we probably will see more change. A change in the way in which the risk margin is calculated would be an obvious example, if we change underlying cost of capital and the impact that then has on the transitional. I will be amazed if things remain static over the next few years. 